\title{
BMJ Global Health Patterns of demand for non-Ebola health services during and after the Ebola outbreak: panel survey evidence from Monrovia, Liberia
}

\author{
Ben Morse, ${ }^{1}$ Karen A Grépin, ${ }^{2}$ Robert A Blair, ${ }^{3}$ Lily Tsai ${ }^{1}$
}

To cite: Morse B, Grépin KA, Blair RA, et al. Patterns of demand for non-Ebola health services during and after the Ebola outbreak: panel survey evidence from Monrovia, Liberia. BMJ Global Health 2016;1:e000007. doi:10.1136/bmjgh-2015000007

- Additional material is available. To view please visit the journal (http://dx.doi.org/ 10.1136/bmjgh-2015000007)

Received 31 October 2015 Revised 9 March 2016 Accepted 1 April 2016

CrossMark

\footnotetext{
${ }^{1}$ Political Science Department, Massachusetts Institute of Technology, Cambridge, Massachusetts, USA

${ }^{2}$ Robert F. Wagner Graduate School of Public Service, New York University, New York, New York, USA ${ }^{3}$ Department of Political Science and Watson Institute for International and Public Affairs, Brown University, Providence, Rhode Island, USA
}

Correspondence to Dr Benjamin Morse; bmorse@mit.edu

\section{ABSTRACT}

Introduction: The recent Ebola virus disease (EVD) outbreak was unprecedented in magnitude, duration and geographic scope. Hitherto there have been no population-based estimates of its impact on non-EVD health outcomes and health-seeking behaviour.

Methods: We use data from a population-based panel survey conducted in the late-crisis period and two postcrisis periods to track trends in (1) the prevalence of adult and child illness, (2) subsequent usage of health services and (3) the determinants thereof.

Results: The prevalence of child and adult illness remained relatively steady across all periods. Usage of health services for children and adults increased by $77 \%$ and $104 \%$, respectively, between the late-crisis period and the postcrisis periods. In the late-crisis period, (1) socioeconomic factors weakly predict usage, (2) distrust in government strongly predicts usage, (3) direct exposure to the EVD outbreak, as measured by witnessing dead bodies or knowing Ebola victims, negatively predicts trust and usage and (4) exposure to government-organised community outreach predicts higher trust and usage. These patterns do not obtain in the post-crisis period. Interpretation: Supply-side and socioeconomic factors are insufficient to account for lower healthseeking behaviour during the crisis. Rather, it appears that distrust and negative EVD-related experiences reduced demand during the outbreak. The absence of these patterns outside the crisis period suggests that the rebound after the crisis reflects recovery of demand. Policymakers should anticipate the importance of demand-side factors, including fear and trust, on usage of health services during health crises.

\section{INTRODUCTION}

The recent outbreak of Ebola virus disease (EVD) has been unprecedented in magnitude, duration and geographic spread. As of 5 August 2015, it has caused over 27862 cases and 11281 deaths in Guinea, Liberia and Sierra Leone. ${ }^{1}$ Roughly $40 \%$ of all cases and deaths were recorded in Liberia.

\section{Key questions}

What is already known about this subject?

- Model-based studies on the impact of the Ebola outbreak on health outcomes in heavily affected countries have predicted large increases in non-Ebola morbidity due to declines in the use of preventative and curative services. However, these studies rely on modeling assumptions and/or extrapolation from precrisis data rather than population-based estimates of health service utilisation during the crisis.

\section{What are the new findings?}

- We use panel data from a household survey conducted in the late-crisis (December 2014) and two postcrisis periods (March 2015 and June 2015) to estimate the prevalence of health service utilisation for adult and child illness in Monrovia, Liberia. We document a $77 \%$ increase in health service utilisation for child illness and a 104\% increase for adult illness between December 2014 and March 2015. These increases persist through June 2015. We find that distrust in government, knowing victims or witnessing dead bodies negatively predict health service usage, while experience with government-organised community outreach positively predicts usage during the crisis.

- In Monrovia, health service utilisation rebounded rapidly after the end of the crisis. The recovery cannot be explained by supply-side or socioeconomic factors. Rather, distrust in government and negative experiences during the outbreak appear to be a major reason why people did not use health services during the outbreak. After the crisis, utilisation quickly recovered.

Recommendations for policy and practice

- Policymakers should anticipate the influence of demand-side factors, including trust and negative EVD-related experiences, on usage of health services during health crises. Building trust through community outreach may be an effective intervention to increase the resilience of health systems during epidemics.

While the direct effects of the outbreak on EVD mortality have been estimated in official figures, little is known about the outbreak's 
indirect effects on non-EVD health outcomes or healthseeking behaviour. Although previous research suggests the indirect effects of EVD are likely substantial, ${ }^{2}$ these studies have predominantly relied on extrapolation from pre-existing data on health-seeking behaviour to estimate potential health impacts. Many of these predictions are quite dire, but their severity depends on the validity of the underlying assumptions about reduced health service utilisation. Moreover, few of these studies allow for behavioural change during the outbreak, which can also influence patterns of demand of health services.

The outbreak had a devastating effect on affected countries. During its peak, most employers, government institutions, non-governmental organisations (NGOs) and international corporations ceased operations, causing widespread unemployment and increased food insecurity. ${ }^{3}$ Incidents of civil unrest flared throughout the region, and states of emergency further limited economic activity. In Liberia, the government declared a state of emergency that was in effect from early August through mid-November, closed schools, imposed a curfew and limited public gatherings. Household quarantines were common, and citizens were encouraged to stay home and prevent the entry of strangers into their community.

Theoretically, the outbreak may have indirectly affected non-EVD health outcomes through several channels, the most obvious of which is the massive disruption to health systems in affected countries (we refer to this set of factors as 'supply-side' factors). By the end of March 2015, roughly 3-4\% of the health workforce in select health professional categories had become infected, and at least two-thirds of those had died. ${ }^{4}$ As much as $8 \%$ of Liberia's stock of doctors, nurses and midwives may have been lost to the disease. ${ }^{5}$ The outbreak disrupted the delivery of non-EVD health services, including routine immunisation, ${ }^{6}$ maternal and child health programmes, ${ }^{78}$ malaria control ${ }^{9}$ and HIV treatment services. ${ }^{10}$ As a result, it has been estimated that maternal mortality may have doubled, and child mortality rates may have risen by $20 \%$ in Liberia. ${ }^{5}$ During the peak of the outbreak, many health facilities were closed due to the lack of staff, many of whom stayed home due to fear of contracting the disease. ${ }^{11}$ However, some of the health system changes may have had positive effects: efforts to promote handwashing and a reduction in contact between individuals may have contributed to a lower incidence of diarrheal or other infectious diseases.

Beyond its effect on health systems, Ebola may have affected demand-side factors that influence healthseeking behaviour. The crisis brought risk and uncertainty to affected communities, particularly during the peak of the epidemic. ${ }^{12}$ Rumours that Ebola was a government conspiracy were common in all three of the highly affected countries. ${ }^{13}$ As a result, sick people may have stayed home because they lacked trust in public services or feared contracting the virus. Indeed, trust has been associated with usage of health services in Liberia and other contexts. ${ }^{14}$ Direct exposure to the outbreaksuch as knowing Ebola victims, witnessing dead bodies or other traumatic experiences-may have further increased fear and distrust.

The response of governments, NGOs and communities may also have affected demand for health services. In the case of Liberia, the Ministry of Health and Social Welfare and international NGOs (INGOs) conducted community outreach to build trust and increase compliance with prevention policies. ${ }^{11}$ These efforts commonly involved door-to-door canvassing by government-sponsored or NGO-sponsored workers to educate residents about proper preventative techniques and inform residents about the response efforts by government and NGOs. These activities could have increased demand for health services if they served to dispel rumours, build trust in authority or reduce fear. ${ }^{15}$

Understanding the outbreak's non-EVD health impactsand the pathways by which they occur-is essential for rebuilding the health system in Ebola-affected countries and for improving the response to future health crises. ${ }^{16}$ Using panel household survey data collected in the latecrisis and postcrisis periods in Monrovia, Liberia, this paper documents trends in the prevalence of reported illness and subsequent health-seeking behaviour. It also documents the determinants of health service utilisation during the late-crisis and postcrisis periods.

\section{METHODS \\ Data}

Data are from a face-to-face household survey conducted in Monrovia, Liberia, from 6 December 2014 to 7 January 2015, as well as two follow-up cellphone surveys conducted from 16 March 2015 to 3 April 2015 and 10 June 2015 to 7 July 2015 . All surveys were conducted by Parley, a Liberian NGO, in collaboration with the authors. We refer to December 2014 as the 'late-crisis' period, which was about 2 months after the peak of the outbreak still affected by active transmission and the epidemic's economic and social impacts. We refer to March and June as the 'postcrisis' periods. See the online supplementary appendix for a more detailed discussion of the dynamics of the outbreak in Liberia.

The sampling design is summarised in figure 1 . The selection of survey respondents for the December survey followed a three-stage sampling procedure. In the first stage, 77 enumeration areas (EAs) were randomly selected from all of Monrovia's 15 administrative wards in proportion to their population size, as enumerated in the 2008 census. In the second stage, roughly 20 households were randomly selected within each EA following a random walk procedure. Following an introduction, a single adult respondent was randomly selected for the survey in the selected household, resulting in a study population of 1572. Surveys were conducted on the spot or scheduled for within $48 \mathrm{~h}$. If the selected respondent 
Figure 1 Sample design.

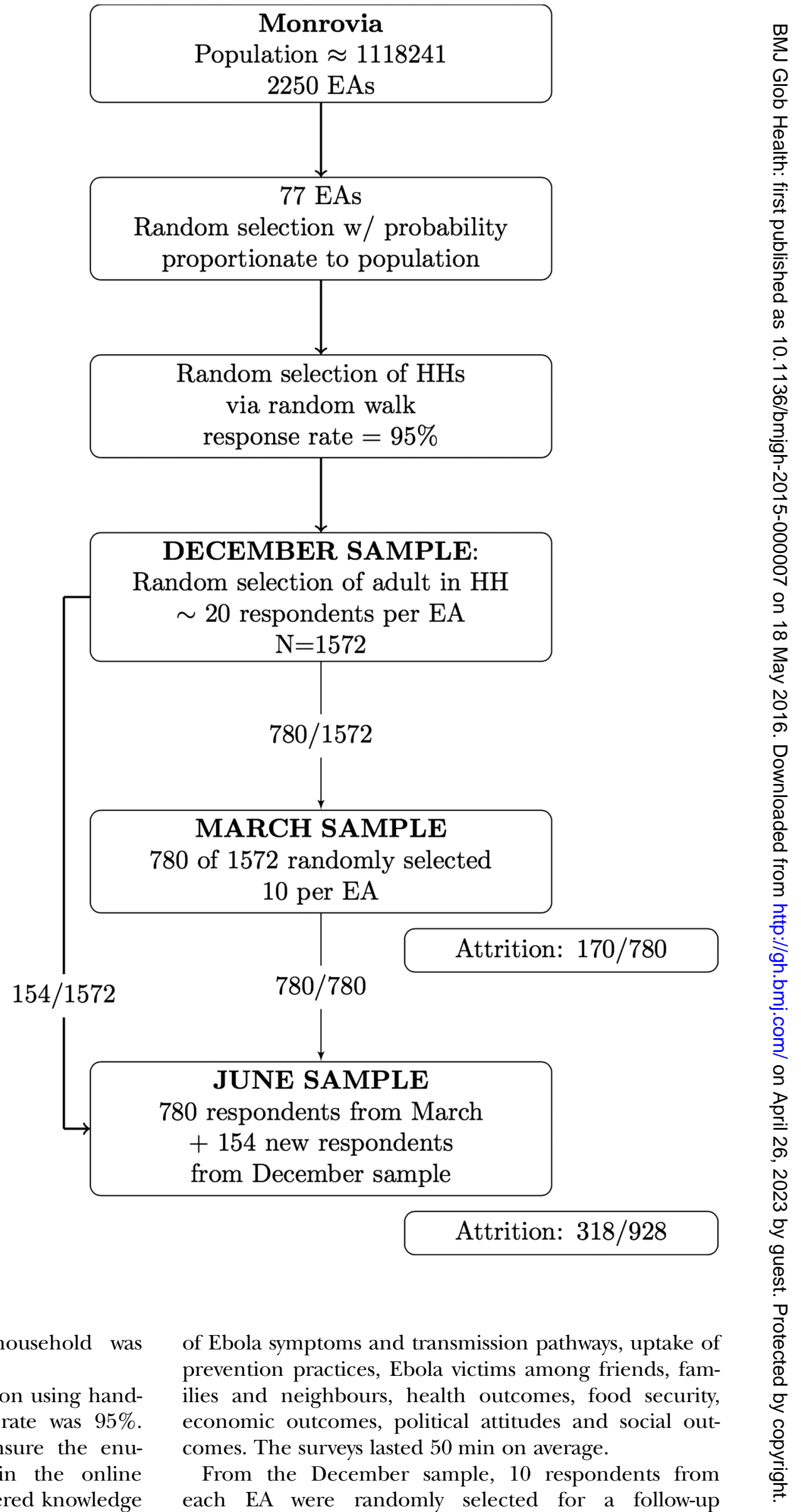

was not available within $48 \mathrm{~h}$, the household was replaced.

Enumerators conducted surveys in person using handheld electronic devices. The response rate was $95 \%$. Extensive precautions were taken to ensure the enumerators' safety, which are outlined in the online supplementary appendix. The survey covered knowledge

\section{Monrovia}

$2250 \mathrm{EAs}$

\section{EAs}

andom selection w/ probability

proportionate to population

\section{DECEMBER SAMPLE}

ndom selection of adult in $\mathrm{HH}$

20 respondents per EA

$\mathrm{N}=1572$

$780 / 1572$

MARCH SAMPLE

80 of 1572 randomly selected 10 per EA

$780 / 780$

Attrition: $170 / 780$ 
cellphone survey in March $(\mathrm{n}=774)$. Follow-up surveys lasted $25 \mathrm{~min}$ on average. Attrition was 22\% (170/774) due to the non-ownership of a phone at baseline (40/ $170)$ or inactive numbers $(124 / 170)$, which compares favourably with other contemporaneous phone surveys conducted in Liberia. ${ }^{17} 18$ Six participants declined to participate in the follow-up survey. The same sample of 774 respondents was selected for follow-up in June, and a new random sample of 154 respondents was selected from the remaining December sample. Attrition was $34 \%$ (316/928). Regression analysis indicates that low education and the 18-25 age group positively predict attrition, but few other sociodemographic variables are statistically significant predictors (see online supplementary appendix). Observations from March and June are weighted to account for differential attrition probabilities in all statistical analyses.

Replication data and programming files for the analyses presented here are available through the Harvard Dataverse. Data are available through the United Nations Office for the Coordination of Humanitarian Affairs' data exchange. ${ }^{19}$

\section{Outcome variables}

We analyse reported rates of illness and subsequent usage of health services for children and adults. Child illness is defined as having any child in the household under 5 years old with a fever or cough in the past 2 weeks. Usage of services for child illness is an indicator variable coded as 1 if the respondent answered affirmatively to the follow-up question: 'Did you go to a hospital, clinic, or other health facility?' In December, we did not inquire how many children were sick or distinguish the usage of services for multiple sick children. In March and June, we inquired how many children were sick and whether care was sought. If a family reported multiple sick children, we average the indicator to maintain comparability with December. We also inquired where care was sought, but only in March and June. The most common providers were hospitals, clinics and pharmacies (see online supplementary appendix table 2). Adult illness is defined as whether a respondent or household member 'felt sick enough to need medical treatment' in the past 3 months, and whether they sought care outside the home for the illness. Hospitals, clinics and pharmacies were the most common providers used for adult illness (see online supplementary appendix table 2). Usage for child illness mirrors the patterns for adult usage, which was worded consistently across survey rounds.

\section{Explanatory variables}

We consider the influence of socioeconomic factors and experiences during the crisis on usage of health services. Here, we consider four demand-side explanatory variables that may account for variation in usage during the crisis based on the introductory discussion: (1) distrust in government institutions, an index of government integrity, trustworthiness, capacity and intentions; (2) the number of confirmed or suspected Ebola victims the respondent personally knew; (3) the number of times the respondent reported that the retrieval of a body from his/her neighbourhood was delayed; and (4) the frequency of interaction with government-sponsored canvassers conducting Ebola-related, door-to-door outreach from August to December 2014 (these questions were added late to our survey; accordingly, the sample size is smaller). In online supplementary appendix table 6 , we additionally consider distance to health centres, pre-Ebola income, current income, trust in INGOs and generalised trust. Trust in government institutions is measured separately in each survey round. Otherwise, all explanatory variables are measured in December. All variables are self-reported. Detailed information on the construction of these variables is provided in the online supplementary appendix.

\section{Ethics approval}

We obtained approval from the institutional review board at the Massachusetts Institute of Technology and in-country approval from the Peacebuilding Office at the Ministry of Internal Affairs. Verbal informed consent was obtained from all respondents.

\section{Statistical methods}

We organise our data as an unbalanced panel of 2788 observations. This includes 1572 respondents from December 2014, 604 observations from March 2015 and 612 observations from June 2015.

In addition to trends over time, we are interested in the determinants of health-seeking behaviour in the latecrisis period relative to the postcrisis period. Accordingly, we interact each explanatory variable with indicator variables for these two periods.

We use logistic regression and report ORs. We control for gender, six age group indicators, log of pre-Ebola income (retrospectively reported), distance to health centres, household size, religion, trust in INGOs, current income, current employment status and trust in other community members. Each of these control variables is interacted with the late-crisis and postcrisis indicators. We also include controls for the administrative ward of residence (there are 15 wards in Monrovia).

In the online supplementary appendix, we present models with (A) no controls, (B) demographic controls and $(\mathrm{C})$ demographic controls with ward fixed effects.

\section{RESULTS}

Table 1 provides a summary of the sample. In the December sample, $56 \%$ of respondents were female, $20 \%$ had secondary school or higher education and the average age was 36 . Respondents reported low levels of trust in government authority: only $24 \%$ reported that 
they trusted the government and $72 \%$ believed it was corrupt. These statistics remain relative steady across the three survey waves.

Figure 2 displays the prevalence of illness and health service utilisation for children and adults across the three rounds, along with the 95\% CIs. Prevalence remains relatively steady across the three time periods. In December 2014，33\% (366/1114) of households reported that at least one child was sick in the past 2 weeks, and 20\% (316/1557) of households reported that at least one adult in the household was sick in the past 3 months. In March 2015, the prevalence of child and adult illness was 22\% (110/498) and $18 \%$ (110/ $605)$, respectively. In June 2015, the prevalence of child and adult illness was 35\% (171/485) and 21\% (131/ $618)$, respectively. Notably, the prevalence of child illness was lower in March 2015 relative to the other time periods (12 percentage points lower compared with December 2014).

Figure 2 indicates a large increase in the usage of health services after the late-crisis period. In December 2014, $48 \%$ (178/368) of households with sick children visited a healthcare provider. By March 2015, usage increased to $85 \%(89 / 105)$, equivalent to a $77 \%$ increase relative to the late-crisis period. This high level of utilisation persists through June 2015, when 83\% $(133 / 162)$ of households with sick children sought care. A similar pattern is observed for the treatment of adult illness. In December, 47\% (149/317) of sick adults sought care, but in March, 96\% (107/111) of sick adults sought care, and $94 \%(124 / 132)$ of sick adults sought care in June.

Table 2 analyses the determinants of health-seeking behaviour in the late-crisis and postcrisis periods. Among the explanatory variables considered in this study, distrust in government strongly and negatively correlated with usage during the crisis period. Outside the crisis period, distrust in government has no association with usage. Direct exposure to the EVD outbreak, as measured by the observation of dead bodies or knowing Ebola victims, is also negatively associated with usage during the crises, but not the late-crisis period. In the late-crisis period, knowing one additional victim of Ebola is associated with an OR of 0.93 for access to healthcare for child illness and an OR of 0.75 for access to healthcare for adult illness. Table 2 also shows that a one-SD increase in experience with government-organised outreach is associated with an OR of 2.01 for access to care for child illness and an OR of 2.79 for access to care for adult illness.

We present four additional analyses in the online supplementary appendix. First, in online supplementary appendix table 5, we show that the results in table 2 are stable across a range of different specifications. Second, in online supplementary appendix table 6 , we show that pre-Ebola income, current income, trust in NGOS and exposure to NGO-organised outreach are weak and inconsistent predictors of usage. Third, in online supplementary appendix table 7, we show that exposure to the Ebola outbreak negatively associates with trust in

Table 1 Sample characteristics

\begin{tabular}{|c|c|c|c|c|c|c|c|c|c|}
\hline Variables & \multicolumn{3}{|c|}{ December 2014} & \multicolumn{3}{|c|}{ March 2015} & \multicolumn{3}{|c|}{ June 2015} \\
\hline \multicolumn{10}{|l|}{ Demographics } \\
\hline Secondary school or above education & $20 \%$ & $40 \%$ & 1572 & $21 \%$ & $41 \%$ & 604 & $21 \%$ & $41 \%$ & 612 \\
\hline Income in normal week pre-Ebola (US\$) & 51 & 73 & 1572 & 50 & 69 & 604 & 52 & 72 & 612 \\
\hline Household size & 7.6 & 4.4 & 1572 & 7.6 & 4.2 & 604 & 7.4 & 4.1 & 612 \\
\hline \multicolumn{10}{|l|}{ Experiences during Ebola crisis } \\
\hline \# of delayed body retrievals reported in neighbourhood & 0.6 & 1.6 & 1572 & 0.6 & 1.6 & 604 & 0.6 & 1.6 & 612 \\
\hline \# of Ebola victims known & 1.4 & 3.6 & 1572 & 1.4 & 3.4 & 604 & 1.5 & 3.6 & 612 \\
\hline Experienced government outreach during crisis & $40 \%$ & $49 \%$ & 1188 & $42 \%$ & $49 \%$ & 450 & $41 \%$ & $49 \%$ & 445 \\
\hline Trusts government & $24 \%$ & $43 \%$ & 1572 & $25 \%$ & $44 \%$ & 604 & $24 \%$ & $43 \%$ & 612 \\
\hline Trusts MOHSW & $26 \%$ & $44 \%$ & 1572 & $34 \%$ & $47 \%$ & 604 & $26 \%$ & $44 \%$ & 612 \\
\hline Believes government is corrupt & $72 \%$ & $45 \%$ & 1572 & $65 \%$ & $48 \%$ & 604 & $69 \%$ & $47 \%$ & 612 \\
\hline Believes MOHSW is corrupt & $67 \%$ & $47 \%$ & 1572 & $54 \%$ & $50 \%$ & 604 & $61 \%$ & $49 \%$ & 612 \\
\hline Distance to health centre $(\mathrm{km})$ & $45 \%$ & $33 \%$ & 1572 & $46 \%$ & $33 \%$ & 604 & $45 \%$ & $34 \%$ & 612 \\
\hline Working less than normal & $64 \%$ & $48 \%$ & 1572 & $70 \%$ & $46 \%$ & 604 & $63 \%$ & $48 \%$ & 612 \\
\hline
\end{tabular}

Variation in sample size within samples is due to non-response or missingness.

INGO, international non-governmental organisation; MOHSW, Ministry of Health and Social Welfare. 


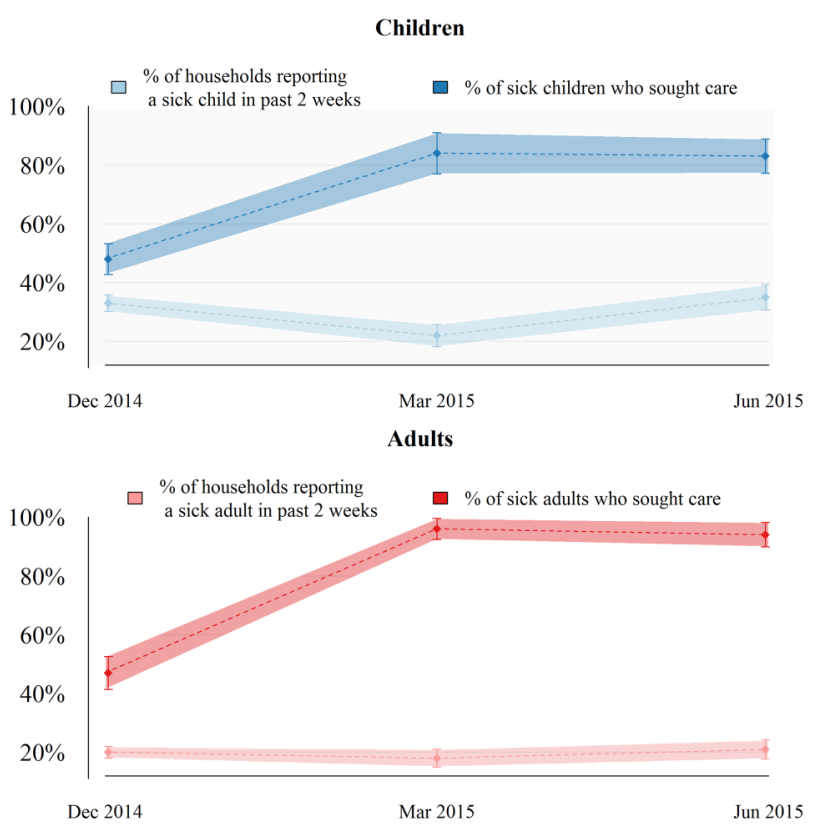

Figure 2 Prevalence of illness and health service utilisation for children and adults over time. government, but only in the late-crisis period. Similarly, government outreach associates positively with trust, primarily in the crisis period. Last, in online supplementary appendices tables 8 and 9 , we consider whether the latecrisis patterns reported in table 2 represent a causal relationship. To do so, we show relative balance on pre-Ebola observables and use a sensitivity analysis to show that the influence of unobserved and omitted factors would have to be substantially more influential than the included variables in order to confound a causal interpretation.

\section{DISCUSSION}

This study documents a $77 \%$ increase in the usage of health services for child illness between the late-crisis period and March 2015. Adult usage increased by $104 \%$ during the same period. This finding suggests that health-seeking behaviour in Monrovia rebounded quickly as the epidemic receded in early 2015. Given the magnitude of the outbreak, as well as its welldocumented adverse effects on the health system, it is

Table 2 Determinants of health service usage during the late-crisis and postcrisis periods

\begin{tabular}{|c|c|c|c|c|c|c|c|c|}
\hline & & (2) & (3) & (4) & (5) & (6) & (7) & (8) \\
\hline & \multicolumn{4}{|c|}{$\begin{array}{l}\% \text { of sick children in } \mathrm{HH} \text { who } \\
\text { accessed care }\end{array}$} & \multicolumn{4}{|c|}{ Adult sick and accessed care } \\
\hline \multicolumn{9}{|l|}{ Late-crisis period } \\
\hline \multirow[t]{2}{*}{ Distrust in government } & 0.66 & & & & 0.75 & & & \\
\hline & $(0.07)^{\star \star \star}$ & & & & $(0.10)^{\star \star}$ & & & \\
\hline \multirow[t]{2}{*}{ \# of delayed body retrievals reported } & & 0.87 & & & & 0.75 & & \\
\hline & & $(0.05)^{\star \star}$ & & & & $(0.06)^{\star * *}$ & & \\
\hline \multirow[t]{2}{*}{ \# of EVD victims known } & & & 0.93 & & & & 0.92 & \\
\hline & & & $(0.02)^{\star \star}$ & & & & $(0.03)^{\star \star}$ & \\
\hline \multirow[t]{2}{*}{ Experienced government outreach during crisis } & & & & 2.01 & & & & 2.79 \\
\hline & & & & $(0.32)^{\star \star \star}$ & & & & $(0.56)^{\star * \star}$ \\
\hline \multicolumn{9}{|l|}{ Postcrisis period } \\
\hline \multirow[t]{2}{*}{ Distrust in government } & 1.10 & & & & 0.68 & & & \\
\hline & $(0.20)$ & & & & $(0.20)$ & & & \\
\hline \multirow[t]{2}{*}{ \# of delayed body retrievals } & & 1.07 & & & & 0.854 & & \\
\hline & & $(0.13)$ & & & & $(0.16)$ & & \\
\hline \multirow[t]{2}{*}{ \# of Ebola victims known } & & & 0.99 & & & & 0.92 & \\
\hline & & & $(0.04)$ & & & & $(0.06)$ & \\
\hline \multirow[t]{2}{*}{ Experienced government outreach during crisis } & & & & 1.05 & & & & 1.90 \\
\hline & & & & $(0.22)$ & & & & $(1.13)$ \\
\hline Observations & 613 & 635 & 635 & 450 & 528 & 548 & 548 & 386 \\
\hline Control variables & $Y$ & $Y$ & $Y$ & $Y$ & $Y$ & $Y$ & Y & $Y$ \\
\hline Ward fixed effects & Y & Y & Y & Y & Y & Y & Y & Y \\
\hline Round fixed effects & Y & Y & $\mathrm{Y}$ & Y & $\mathrm{Y}$ & Y & Y & Y \\
\hline
\end{tabular}

Robust SEs in parentheses. ${ }^{* \star *} p<0.01,{ }^{* \star} p<0.05,{ }^{*} p<0.1$ Logistic regression with ORs reported. OR SEs clustered by enumeration area. Estimates weighted by inverse attrition probabilities. Variation in sample size across models is due to either applicability or non-response. EVD, Ebola virus disease; $\mathrm{HH}$, household. 
not surprising to observe lower levels of usage in December. However, it is surprising how quickly rates of health-seeking behaviour have rebounded. None of the previous studies of the outbreak's health impact have taken into consideration the recovery of health service utilisation, suggesting that these earlier studies likely overestimate the adverse effects of the outbreak.

The determinants analysis provides suggestive insight into why usage was lower in the late-crisis period, and why it rebounded so quickly. First, the fact that demand-side factors determine usage during the latecrisis period implies supply-side factors cannot entirely account for the recovery. In addition, the recovery is unlikely to reflect changes in income or employment, as these outcomes improve only marginally in the postcrisis period.

Instead, we see distrust in government and exposure to negative EVD-related experiences as among the most important determinants considered in this study. As reported in table 2, distrust is the strongest determinant of reduced usage during the late-crisis period. Distrust has no association with usage outside the crisis period, indicating that this pattern is unlikely to reflect inherent differences in health-seeking behaviour between hightrust and low-trust individuals. While it is possible that experiences at the clinic influenced trust in government rather than vice versa, the absence of a relationship outside of the late-crisis period weighs against this possibility. It is also unlikely that fear of Ebola contagion at health centres is driving distrust, rather than vice versa. If this were true, we would expect distrust to decline once the epidemic is declared over. Yet, our index of distrust reduces by only $5 \%$ between December 2014 and early June 2015, when Liberia was Ebola free. More generally, if a confounding variable were to account for the relationship between distrust and usage, the degree of confounding would need to change between the late-crisis and postcrisis periods.

Instead, we interpret our results as suggestive evidence that trust becomes more important during health crises characterised by high levels of risk and uncertainty. Citizens facing a previously unknown, traumatic disease amid widespread rumours of government conspiracy are unlikely to use health facilities if they distrust the government or its capacity to ensure that health facilities are safe from Ebola. Outside the crisis period, risk and uncertainty no longer pervade, and trust takes on a more muted role.

Exposure to the EVD outbreak, as measured by knowing Ebola victims or reporting delayed retrieval of dead bodies, also negatively predicts usage (and increases distrust) during the late-crisis period. The fact that affected individuals do not have different levels of usage or trust outside the crisis indicates they are not inherently different from less-affected individuals. We interpret these findings as further suggestive evidence that a climate of fear interacted with distrust in authority to decrease usage of health facilities.

The positive association between government outreach and health service usage also suggests that trust played an important role during the epidemic. Outreach was intended to build trust and compliance with preventative measures, and entailed door-to-door canvassing by community volunteers trained by the government. These activities may have increased demand for health services if they served to dispel rumours, build trust in authority or reduce fear.

There are several limitations to our study. First although we consider a wide range of social, economic and demographic determinants of usage, it is possible that factors beyond those considered were also important. As we did not measure these factors, we cannot assess how they compare to those documented in this study.

A related limitation is that we did not enquire about the severity or type of reported illnesses. It is therefore possible that changes in the severity or type of reported illnesses account for the recovery between December and March. However, since the overall prevalence rates of reported illness remained relatively stable over the study, we think it is unlikely that seasonal or other changes in the disease burden would be large enough to explain the $77 \%$ and $104 \%$ increase in usage rates that we observed for child and adult illness, respectively.

Our data only cover Monrovia, and the patterns observed in our sample may not apply elsewhere, in particular to rural areas where access to health services is more limited. Aside from our measure of adult usage, which uses a 3-month recall, our data do not cover the peak of the outbreak. Therefore, our data on child usage will not capture drops in usage that occurred at the peak of the outbreak. Regarding the correlates analysis, given the 3-month recall, it is possible that adult usage temporally preceded our key explanatory variables (ie, knowing Ebola victims, witnessing dead bodies and government outreach). Since reverse causation is implausible, this bias will serve to attenuate the patterns reported in table 2. Attenuation will be minimal if these experiences were concentrated during or before height of the epidemic, which corresponds to the end of the recall period. Indeed, according to official WHO data, the overwhelming majority of cases in Liberia occurred before October 2014. Nonetheless, we caution that our analysis may underestimate the correlations reported in table 2 for adult usage (but not child usage).

A final limitation is that the wording of our questions was not entirely comparable with questions asked in other household surveys, such as the Demographic and Health Survey, which prevents us from making direct comparisons with external data to benchmark our findings.

Overall, our analysis suggests supply-side and socioeconomic factors are insufficient to explain patterns of 
health service usage during the crisis. Rather, demandside factors were important determinants of healthseeking behaviour during the outbreak. Fear, distrust in government and exposure to negative EVD-related experiences likely reduced demand for health service usage during the crisis, while exposure to governmentorganised outreach likely increased demand. The absence of these associations, together with the tendency of supply-side factors to recover slowly, suggests the rebound in usage after the crisis reflects recovery of demand.

This paper demonstrates that some of the reduction in health-seeking behaviour during the outbreak was likely due to demand-side factors, such as trust in government and fear. Responders interested in sustaining health systems during epidemics should evaluate the potential influence of fear and trust in government, and consider whether interventions to promote care-seeking behaviour by building trust and reducing fear are warranted. This paper provides suggestive evidence that community outreach is effective in this regard. However, more research on this topic is warranted.

Handling editor Seye Abimbola

Twitter Follow Karen Grepin at @KarenGrepin

Contributors $\mathrm{LT}, \mathrm{BM}$ and RAB designed the study. BM oversaw data collection and performed data analysis. BM and KAG drafted the manuscript. All authors contributed to the framing, interpretation and conclusions.

Funding This project received financial support from the Omidyar Network, the International Growth Centre, and the School of Humanities, Arts, and Social Sciences at MIT.

Competing interests None declared.

Ethics approval MIT COUHES.

Provenance and peer review Not commissioned; externally peer reviewed.

Data sharing statement No additional data are available.

Open Access This is an Open Access article distributed in accordance with the Creative Commons Attribution Non Commercial (CC BY-NC 4.0) license, which permits others to distribute, remix, adapt, build upon this work noncommercially, and license their derivative works on different terms, provided the original work is properly cited and the use is non-commercial. See: http:// creativecommons.org/licenses/by-nc/4.0/

\section{REFERENCES}

1. World Health Organization. Ebola Situation Report. apps.who.int. 2015; published online 5 August. http://apps.who.int/ebola/currentsituation/ebola-situation-report-5-august-2015 (accessed 10 Aug 2015).

2. Helleringer S, Noymer A. Magnitude of Ebola relative to other causes of death in Liberia, Sierra Leone, and Guinea. Lancet Glob Health 2015;3:e255-6.

3. Bowles J, Hjorth J, Melvin T, et al. Ebola, jobs and economic activity in Liberia. J Epidemiol Community Health 2016;70:271-7.

4. The World Health Organization. Health worker Ebola infections in Guinea, Liberia and Sierra Leone. WHO, 2015; published online 21 May. http://www.who.int/csr/resources/publications/ebola/ health-worker-infections/en/ (accessed 29 May 2015).

5. Evans DK, Goldstein M, Popova A. Health-care worker mortality and the legacy of the Ebola epidemic. Lancet Glob Health 2015;3: e439-40.

6. Takahashi S, Metcalf CJE, Ferrari MJ, et al. Reduced vaccination and the risk of measles and other childhood infections post-Ebola. Science 2015;347:1240-2.

7. Menéndez $\mathrm{C}$, Lucas $\mathrm{A}$, Munguambe $\mathrm{K}$, et al. Ebola crisis: the unequal impact on women and children's health. Lancet Glob Health 2015;3:e130.

8. Check Hayden E. Maternal health: Ebola's lasting legacy. Nature 2015:519:24-6.

9. Walker PGT, White MT, Griffin JT, et al. Malaria morbidity and mortality in Ebola-affected countries caused by decreased health-care capacity, and the potential effect of mitigation strategies: a modelling analysis. Lancet Infect Dis 2015;15:825-32.

10. Tattevin P, Baysah MK, Raguin G, et al. Retention in care for HIV-infected patients in the eye of the Ebola storm: lessons from Monrovia, Liberia. AIDS 2015;29:N1-2.

11. Nyenswah T, Fahnbulleh M, Massaquoi M, et al. Ebola epidemicLiberia, March-October 2014. MMWR Morb Mortal Wkly Rep 2014;63:1082-6.

12. Abramowitz SA, McLean KE, McKune SL, et al. Community-centered responses to Ebola in Urban Liberia: the view from below. PLoS Negl Trop Dis 2015;9:e0003706.

13. Mundasad S. Ebola virus: busting the myths. BBC News. 2014 published online September 22.

14. Svoronos T, Macauley RJ, Kruk ME. Can the health system deliver? Determinants of rural Liberians' confidence in health care. Health Policy Plan 2015;30:823-9.

15. Fast SM, Mekaru S, Brownstein JS, et al. The role of socia mobilization in controlling Ebola virus in Lofa County, Liberia. PLoS Curr 2015;7. doi:10.1371/currents.outbreaks.c3576278c66b22ab54a 25e122fcdbec1

16. Kruk ME, Myers M, Varpilah ST, et al. What is a resilient health system? Lessons from Ebola. Lancet 2015;385:1910-12.

17. The Socio-Economic Impacts of Ebola in Sierra Leone. worldbank. org. http://www.worldbank.org/en/topic/poverty/publication/ socio-economic-impacts-ebola-sierra-leone (accessed 24 Aug 2015).

18. Himelein K, Kastelic JG. The socio-economic impacts of Ebola in Liberia. World Bank Working Paper 2015:1-19.

19. MIT Governance Lab. Data for Ebola Recovery. Humanitarian Data Exchange. 2015; published online 1 June. https://data.hdx.rwlabs. org/dataset/data-for-ebola-recovery (accessed 15 Aug 2015). 